\title{
Obediencias negociadas y desobediencias silenciadas en la Compañía de Jesús en España, ss. XVI-XVII ${ }^{1}$
}

\author{
Doris Moreno Martínez \\ Universidad Autónoma de Barcelona
}

RESUMEN: La Compañía de Jesús no fue una protagonista monolítica de la modernidad disciplinante sino un prisma de muchas caras, reflejo de la complejidad del paradigma tridentino. Uno de esos prismas tiene relación con el disentimiento interno y su gestión a lo largo de los ss. XVI y XVII, en una institución que hizo de la obediencia piedra clave de su edificio. Se aborda en el artículo la normativa de la Compañía sobre la disidencia y la dimisión, las atribuciones otorgadas por los Papas a los Generales respecto a los jesuitas rebeldes y las actitudes hacia los salidos cuajadas en los textos de la Compañía (Bobadilla, Ribadeneira, Andrade). Se subraya que, frente a estas narrativas de retribución, la Compañía moduló la norma, negoció la obediencia, atendiendo a criterios de escándalo y reputación. En esta clave, se aborda el caso del jesuita Francisco Abreo y sus tácticas para lograr una situación ventajosa a cambio de su silencio, apelando a la Inquisición española como recurso. El resentimiento de algunos exjesuitas les llevó a escribir textos como el Mónita secreta que, a finales del siglo XVII, no sólo alimentaba el antijesuitismo sino también la posibilidad de un cambio de gobierno de la Monarquía española.

\section{PALABRAS CLAVE: Obediencia; disentimiento; jesuitas; Inquisición; antijesuitismo; confesionalización.}

1 Abreviaturas de archivos y fuentes impresas: Archivo de la Embajada de Asuntos Exteriores (AA.EE., Santa Sede). Archivo Histórico de la Compañía de Jesús en Cataluña (AHSIC), Sección Antiga Compañía. Archivum Storicum Societatis Iesu (ARSI). Archivo Secreto Vaticano (ASV). Archivo Histórico Nacional (AHN). Monumenta Histórica Societatis Iesu (MHSI). Memorial Histórico Español (MHE). Proyectos en los que se inscribe este trabajo del Ministerio de Economía y Competitividad: RyC-2008-02585 y HAR2011-26002; de la Generalitat de Catalunya: 2009SGR0329. 
Negotiated Obedience and Silenced Disobedience in the Society of Jesus in Spain. XVIth and XVIIth Centuries

ABSTRACT: The Society of Jesus was not a monolithic character of disciplining modernity but a prism of many sides, reflecting the complexity of the Tridentine paradigm. One of these prisms is related to internal dissent and its management along XVIth and XVIIth, in an institution that made obedience the keystone of its building. The rules of the Company about the dissent and the expulsion, the privileges granted by the Popes to the Generals regarding the rebel Jesuits and the attitudes towards the expelled in the texts of the Company (Bobadilla, Ribadeneira, Andrade) are approached in this article. It is emphasized that, in front of these narratives of remuneration, the Company modulated the rule, negotiated obedience, according to criteria of scandal and reputation. In this key of interpretation, the autor studies the case of the Jesuit Francisco Abreo and his tactics to achieve an advantageous situation in exchange for his silence, appealing to the Spanish Inquisition as a resource. The bitterness of some exjesuits led them to write texts like Mónita secreta that not only fed the antijesuitism but also the possibility of a change of government in the Spanish Monarchy at the late seventeenth century.

KEY WORDS: Jesuits; obedience; dissentiment; Inquisition; antijesuitism; confessionalization.

\section{UNUS NON SUFFICIT ORBI}

La Compañía de Jesús fue un eficaz instrumento confesionalizador al servicio de una Iglesia tridentina que si en buena medida se pudo llamar triunfante fue gracias a la acción de la Compañía de Jesús, a su militancia activa en el mundo y su disposición de obediencia al Papado. Sus propios logros, la Compañía supo dorarlos, revestirlos y adornarlos con indudable maestría. Los jesuitas dominaron estrategias y recursos que les garantizaran una enorme y positiva proyección mediática, conscientes de que buena parte del éxito y el crédito de su joven orden se basaba en la buena opinión que pudiesen generar.

En 1640 se publicaba en Amberes la Imago primi saeculi, un magnífico volumen in-folio que trataba de recoger los ideales y éxitos alcanzados por la Compañía en su primer siglo. El libro celebraba la gloria de la Compañía, sobre todo a través de sus santos y mártires, y recogía la extensión de la orden por todo el mundo. Aparador de las glorias de la Compañía, la Imago era también una respuesta elegante y erudita al cuestionamiento de la orden al subrayar desde el providencialismo el propósito divino para el mundo católico cumplido en la Compañía: llevar al pueblo a la virtud, enriquecer a la iglesia con nuevos caminos de santidad y combatir a los herejes. El optimismo de la Compañía se expresaba en una de las ilustraciones en las que, Eros, dios 
del amor en forma de niño, abrazaba los dos hemisferios bajo el lema latino «unus non sufficit orbis», un mundo no es suficiente. El poema al pie de la ilustración subrayaba que ni Hércules ni Alejandro habían llegado tan lejos como la Compañía en sus viajes y conquistas. La habilidad de la Compañía para «conquistar» nuevos mundos para Cristo y su iglesia se había demostrado plenamente².

Este orgullo de sus propios méritos y singularidad era un sentimiento plenamente instalado en el cuerpo jesuita. El centenario fue celebrado en todas las casa jesuitas con actos diversos en los que se procuró desplegar todos los recursos para mostrar y demostrar el poder de la Compañía. Las fiestas de Madrid fueron especialmente lucidas, con un despliegue impresionante de participantes, imágenes, estandartes, luminarias... y como escribía el padre Claudio Clemente al jesuita padre Pereyra de Sevilla el 2 de octubre de 1640, «En fin, es la voz común que no se ha visto tal, y que sola la Compañía lo puede hacer» ${ }^{3}$.

A pesar de lo dicho hasta ahora, la Compañía no siempre ganó la batalla de la opinión. Su disolución en 1773 sería la prueba definitiva de ello. Mucho antes de esa fecha, a la construcción de esta imagen positiva de la Compañía con toques de leyenda barroca rosada, se opuso la construcción de un antijesuitismo que se nutrió de las críticas internas, lo que ha permitido hablar justamente del bifrontismo, de la cara y la cruz, de la historia de la Compañía de Jesús ${ }^{4}$. La imagen que la Compañía quiso transmitir fue la de un muro monolítico y compacto. Sin embargo, el disentimiento interno fue una realidad crucial, brechas sangrantes en ese muro que, por un lado, la Compañía quiso tapar para evitar el escándalo, y por otro, se volvió contra ella al difundirse ampliamente entre sus críticos, proporcionando combustible de primera mano para impregnar la hoguera que, a la postre, se encendió en el siglo XVIII ${ }^{5}$.

Estrechamente vinculado al disentimiento y poco tratado historiográficamente, es el problema de los salidos o expulsos de la Compañía, o dimitidos tal y como son mencionados en las Constituciones, tema sobre el que recientemente Sabina Pavone ha llamado la atención 6 . Disidencia y expulsión están íntimamente relacionadas con el tema nuclear de la obediencia en la Compañía de Jesús. Una de las claves de bóveda del edificio jesuita era la doctrina de la obediencia ciega. Ignacio de Loyola había hecho de esta doctrina una de las señas de identidad de su Instituto al exigir de sus miembros la obediencia de acción, de pensamiento y de voluntad. Es cierto que las Constituciones

\footnotetext{
2 FUMAROLI, 1998. SALVIUCCI INSOLERA, 2004.

3 MHE. Cartas de jesuitas, 1862: 19. El subrayado es nuestro.

4 PAVONE, 2010: 229-254.

5 CATTO, 2009. MORENO, 2010: 77-114. GAY, 2012.

6 PAVONE, 2011: 465-479.
} 
admitían la posibilidad de «representar» al superior una opinión o juicio discrepante con la orden recibida; pero, en cualquier caso, el jesuita debía aceptar la decisión última del superior como si fuese un cadáver, imagen de antigua tradición medieval utilizada por Ignacio de Loyola para explicar de manera efectiva el principio de la obediencia ciega. Se esperaba de un súbdito jesuita que estuviese a la completa y absoluta disposición del superior para servicio a la Iglesia. Una obediencia tan intensa y profunda excitaba por reflejo desobediencias múltiples ${ }^{7}$.

El verdadero disidente acabaría expulsado o salido de la Compañía. Sin embargo, antes de llegar a la expulsión se dieron una multitud de situaciones y casuísticas que han permitido hablar de la distancia entre la obediencia normativa y las modulaciones de las formas de obediencia atendiendo a circunstancias, personas y lugar. Antonella Romano sugirió el término «obediencia negociada» frente al de disidencia organizada, una expresión que se adapta bien al dinamismo de la Compañía, a su búsqueda sostenida de micro consensos dentro y fuera de su propia estructura, a su capacidad de reinterpretarse a sí misma en los diferentes nichos de la Reforma católica ${ }^{8}$. Obediencia negociada y desobediencia silenciada serían dos caras de una misma moneda. Ambas realidades fueron la respuesta posibilista de la Compañía a la disidencia de los individuos, respuesta que en ocasiones logró evitar la expulsión pública, el escándalo según la propia orden, y en ocasiones no. ¿Cuál fue la actitud de la Compañía frente a esas disidencias internas y los salidos? ¿Cómo aplicó su propia normativa en estas situaciones? En las relaciones de colaboración entre Roma y la Monarquía española para administrar la llamada Reforma católica pos-tridentina, ¿qué papel jugó la desobediencia jesuítica? ¿Cómo se expresaron los disidentes? ¿Cuáles fueron sus estrategias, mecanismos y objetivos? ¿Cómo se relacionaron esas críticas internas con la construcción de la imagen negativa de la Compañía? Nos proponemos en este artículo hacer aquí una primera exploración de las dimensiones de las grietas que la nave jesuítica fue mostrando a lo largo de los siglos XVI y XVII a través del problema de la disidencia dentro de la Compañía, grietas que a la postre contribuyeron al hundimiento de 1773.

\section{SALIDOS, EXPULSADOS, DIMITIDOS}

La preocupación por los salidos o dimitidos de la Compañía de Jesús ya existió en los mismos inicios de la orden. La expresión «dimitidos», utilizada habitualmente por las fuentes jesuíticas de la época remitía al ámbito jurídico,

7 MORENO, 33 (Valladolid, 2013): 63-88.

8 Citado en ALFIERI y FERLAN, 2012: 7-17. 
a la entrega de cartas dimisorias por parte del General, documento imprescindible para salir de la orden ${ }^{9}$. El uso de esa expresión no aclaraba si la carta dimisoria se había otorgado a iniciativa del súbdito jesuita o del General. También se utilizaban los vocablos «salidos», «despedidos» y con menos frecuencia la expresión «expulsos» 0 «expulsados». Bajo estos conceptos se dieron realidades muy diversas: los que se salieron por enfermedad, los que sufrieron una crisis vocacional, los que fueron calificados de indignos por el General, los fugitivos, los que se pasaron al protestantismo...

El problema de la disidencia y de la expulsión estaba directamente relacionado en muchos casos con el problema de la entrada en la Compañía ${ }^{10}$. Una brecha entre expectativas y realidad que con el tiempo podía desembocar en una crisis vocacional profunda. Este desapego al proyecto jesuítico necesariamente hizo crujir la estructura, tan jerárquicamente organizada sobre los principios de la obediencia. La preocupación por este problema, las quejas y críticas por las prácticas relacionadas y las respuestas internas fueron muy tempranas. Ya en 1559 Nicolás de Bobadilla escribía una epístola consolatoria tras las numerosas bajas que se habían producido en Messina en 1559 por la política de expulsiones que siguió el visitador Juan de Montoya ${ }^{11}$. Pero sin duda la obra más importante y que dejó una huella más indeleble en la Compañía sobre el tema fue el texto nunca editado de Pedro de Ribadeneira, Diálogos en los cuales se trayan algunos ejemplos de personas que habiendo salido de la Religión de la Compañía han sido castigados severamente de la mano de Dios, que se escribieron entre los años 80 del siglo XVI (los dos primeros) y 1607 (el tercero) ${ }^{12}$. Hubo una continuación por parte del padre Alonso de Andrade, también manuscrita, que cubrió el periodo 1607-166213. La razón por la que no se publicó el texto de Ribadeneira la dejó clara Aquaviva en 1602 al responder a la petición de impresión:

9 Voz «Dimisorias» en O’NEILL y DOMÍNGUEZ, I, 2001: 1126-1127; III, voz «Miembros. II. Dimisión»: 2665.

10 LYNN MARTIN, 72/2 (Washington, 1986): 201-221. MIR, 1913, II, cap. 2: 50-80.

11 SCADUTO, 43 (Roma, 1974): 85-101.

12 ACJB, Sección Diversa, signatura ACDI 112-01. Ricardo García Cárcel ya llamó la atención sobre el interés de este texto, GARCÍA CÁRCEL, 2000: 383-404. Ribadeneira tuvo pronto imitadores y su modelo tuvo continuadores tardíos. Paul Shore ha estudiado el manuscrito inédito de János Nádasi, uno de los más prolíficos e influyentes jesuitas húngaros del siglo XVII y confesor de Eleonora, viuda del Emperador Fernando III, titulado Tristes annuae Desertorum que pretendía poner de relieve los desastres que esperaban a los colegiales novicios que dejasen la Compañía, SHORE, XV/2 (Budapest, 2010): 179-192.

13 Andrade, Diálogo $4^{\circ}$ de Sucesos trágicos a los expulsos de la religión, en especial a los que han salido de la Compañía de Jesús desde el año 1607 hasta 1662, ACJB, Sección Diversa, signatura 113-01. 
sacados los nombres de las personas será quitarles toda su fuerza y sacarlos con nombres podrá ser daño... no veo cómo se puede remediar lo de los diálogos sin nota de muchos, de suerte que no nos haga odiosos, por lo cual reparamos tanto en su impresión ${ }^{14}$

Presumiblemente, por el mismo motivo no se editó el texto de Andrade.

Los tres textos ofrecen singularidades. Bobadilla concluía su epístola recomendando la misericordia y la compasión hacia los dimitidos. Ribadeneira era mucho más riguroso en la condena de los salidos, aunque templaba su perspectiva haciendo críticas más o menos veladas al funcionamiento de la Compañía en la captación y seguimiento de los novicios por parte de los superiores, en la cobardía de los superiores al no querer enfrentar a los inferiores en sus vicios y faltas por un deseo de paz mal entendida y en los déficits de ejemplaridad de los jesuitas viejos. Andrade, en cambio, era absolutamente taxativo: los salidos eran los únicos responsables de sus tristes finales. Entre 1559 y 1662 la actitud de la Compañía hacia los salidos se fue radicalizando.

De los tres textos el más conocido fue, sin lugar a dudas, el de Ribadeneira, que a finales del XVI era parcialmente leído a los novicios en el refectorio. Del impacto de esas lecturas tenemos ecos en la continuación de Andrade en la que en varias ocasiones se hace referencia a los diálogos de Ribadeneira como un padrón de sambenitos expuestos: «son como la horca de los ajusticiados por Dios y adonde se ponen los sambenitos de los que han salido de la Compañía» ${ }^{15}$.

Normalizaba Ribadeneira las expulsiones y elevado número. Los ejemplos bíblicos y patrísticos abundaban: de dos hermanos, Caín y Abel, uno era malo y el otro bueno, un 50/50, ¿podía aspirar la Compañía a un porcentaje de expulsión menor? No. La rigurosidad de la Compañía en la formación de los novicios (2 años), el largo proceso de conformación de la identidad jesuita y la aplicabilidad del individuo en los diversos ministerios, la variedad de grados y el particular gobierno de la Compañía, que permitía al General expulsar en cualquier momento, eran también razones explicativas del mismo proceso.

El propósito de Ribadeneira era dar a conocer el riguroso castigo que Dios imponía a los salidos, o bien para que reflexionasen y volviesen sobre sus pasos o bien para que entendiesen que sus desgracias eran el primer padecimiento de las penas que vendrían en la eternidad. En segundo lugar, buscaba Ribadeneira la ejemplaridad para los jesuitas formados. En tercer lugar, dirigía especialmente el texto a los estudiantes de la Compañía, «por el peligro que tienen de desvanecerse con la ciencia y perderse si no viven con muy

\footnotetext{
14 ARSI, Tolet. 6, I, Epp. Gen. 1600/1605: 127.

15 ANDRADE, ACJB, Sección Diversa, signatura 113-01: f. 27.
} 
grande recato» ${ }^{16}$. La ciencia, el conocimiento de las letras, sin recato y obediencia, podían llevar a caminos no recomendables.

No faltaban referencias críticas en los Diálogos de Ribadeneira al funcionamiento cotidiano de la Compañía. Notaba la falta de discernimiento de espíritu y vocación de los superiores, la facilidad en la captación de futuros jesuitas por parte de "consultores y examinadores», la nula resistencia a las presiones internas y externas para aceptar candidatos, la ausencia de exámenes profundos que permitieran detectar las falsas motivaciones de aquellos que se acercaban a la Compañía buscando una formación sólida para salirse una vez lograda, los que esperaban conseguir una red de relaciones, los que se acogían a la Compañía como una huida, etc.

Una vez captado el candidato, la responsabilidad recaía sobre el maestro de novicios el cual debía «hacer anatomía del novicio» para entender si realmente era un sujeto adecuado para la Compañía, enseñar al novicio a conocer los rincones de su conciencia, a examinarse y descubrir sus zonas oscuras, a aprender a doblegar su voluntad y aceptar la obediencia («y sobre todo hágale negar en muchas cosas, aunque sean lícitas, su propia voluntad para que esté más fácil en negarla en las ilícitas, a una parte y a otra para que se haga a todas manos y obediente al freno, y sea blando y flexible y tratable para todo lo que quisiera hacer de él»); al maestro de novicios tocaba también, según Ribadeneira, encuadrar («se embeba y empape») al novicio en el espíritu y modo de proceder de la Compañía, atendiendo especialmente a que «tenga gran cuenta en los modos que tienen en el orar, de meditar, de examinarse y de mortificarse y hacer penitencia» ${ }^{17}$.

Una vez hechos los votos simples el ya jesuita debía continuar tutorizado en los colegios y casas por los superiores. En este nivel, Ribadeneira también apuntaba a los errores que se estaban cometiendo. El rápido crecimiento de la Compañía y las necesidades urgentes habían llevado al gobierno a una nueva generación que no tenía experiencia en la disciplina y el gobierno religioso y, por un lado callaban y dejaban hacer para tener paz con los súbditos y por otro fomentaban un activismo desaforado que estaba enfriando el espíritu y el corazón con consecuencias nefastas: «y con eso pierde el hombre la luz del verdadero conocimiento, y queda ciego como Sansón, atado a la tahona y estar con el cuerpo atado a la Religión y con el corazón fuera de ella» ${ }^{18}$. Tanto Ribadeneira como Andrade enfatizaban uno de los principios de Ignacio de Loyola: importaba infinitamente más el conjunto de la Compañía que uno de sus miembros.

16 RIBADENEIRA, ACJB, Sección Diversa, signatura ACDI 112-01: 8. En el manuscrito manejado no consta número de página. Se anota el número de la imagen.

17 RIBADENEIRA, ACJB, Sección Diversa, signatura ACDI 112-01: 202, 204.

18 RIBADENEIRA, ACJB, Sección Diversa, signatura ACDI 112-01: 191. 
Pasaba Ribadeneira a hacer un análisis de las causas que llevaban a la salida a los jesuitas según sus grados. En los novicios, el problema podía ser una expectativa equivocada y la falta de adecuación al instituto. En los coadjutores, a la inhabilidad para los ministerios de la Compañía podía añadirse el problema de la ambición, del deseo de ser profeso. La falta de espíritu y virtud eran los motivos esenciales de los que se salían (flaqueza ante las dificultades del camino jesuita, dejarse arrebatar por las pasiones y apetitos, ceder a las presiones de los padres...). Con todo, Ribadeneira sugería que la salida de los jesuitas formados se debía a una debilidad de su espiritualidad (falta de oración y trato con Dios), a la desobediencia y fragilidad en la observancia de su regla; la pérdida de respecto y obediencia al superior como ministro de Dios; y la falta de una renovación continua de la vocación ${ }^{19}$. La Compañía de entrada no aceptaba a nadie salido de otra orden para no disgustar a las otras órdenes y, sobre todo, buscando la unanimidad de todos los jesuitas, evitando la «ensalada de institutos y reglas» ${ }^{20}$.

La caracterización de los salidos era la del apóstata de la religión, rebelde, desobediente, individuos «que no se amoldan a su vocación e instituto», incapaces e inútiles. Las consecuencias de abandonar la orden eran terribles y múltiples: físicas (enfermedades de todo tipo, muerte), sociales (el rechazo de las familias y los amigos; la pérdida del crédito personal; la conversión en un marginado: bandolero, jugador, etc...), económicas (la pobreza absoluta al haber renunciado a las riquezas previas y al tener el rechazo del entorno familiar y social), eclesiales (el rechazo a otorgar puestos eclesiásticos a salidos de las órdenes religiosas) y espirituales (pérdida de las virtudes, si alguna vez se tuvieron, peligro cierto de la salvación...). El panorama que se trazaba era terrorífico. Los casos expuestos pretendían demostrar que quedarse en la Compañía era garantía de virtud, pero salir de ella era también garantía de un deslizamiento inevitable «en un abismo de torpezas y maldades» ${ }^{21}$. Por ello, no podía extrañar que después de dejar el puerto seguro de la Compañía, muchos se convirtiesen en asesinos, ladrones, falsarios..., que muchos otros murieran de muerte repentina e inesperada, sin sacramentos, con grave riesgo de su vida eterna... La narrativa de la retribución era de una claridad meridiana: todos los que abandonaban la Compañía después de haber sentido la vocación, aun sin haber vestido formalmente el hábito de novicio, recibirían castigos terribles. Andrade, en la misma línea que Ribadeneira, lo expresaba con plasticidad barroca:

como en la Compañía está abierta la puerta tantos años para poder la religión despedir a los díscolos y tentados en su vocación, la ha querido cerrar Dios con

19 RIBADENEIRA, ACJB, Sección Diversa, signatura ACDI 112-01: 209-210.

20 RIBADENEIRA, ACJB, Sección Diversa, signatura ACDI 112-01: 174.

21 RIBADENEIRA, ACJB, Sección Diversa, signatura ACDI 112-01: 264. 
tantos y tan atroces castigos en los que han salido de ella: para que el temor les sirva de cerca y no se atreva ninguno a traspasar su límite, pues ve la espada y el fuego que juega el Angel del Señor para guardar la de este paraíso²2.

El miedo como alambrada electrificada. Los casos expuestos eran piedras que debían reforzar el muro de la Compañía, aviso para los que quisieran abrir brecha en ese muro y puerto seguro de la fe:

Piedras son todos los casos referidos para reforzar y fortificar el muro de nuestra religión, pues con tanta evidencia se ven los castigos que la mano poderosa de Dios descarga sobre los que se atreven a dejarla y quieren hacer brecha y portillo por donde salgan otros, y puede cada uno entender que debe guardar su puerto y perseverar en su vocación so pena de la vida ${ }^{23}$.

Decíamos que en la franja cronológica en la que se inscriben los textos de Bobadilla, Ribadeneira y Andrade es posible apreciar un cambio de actitud progresivo hacia los salidos. La Compañía fue modulando su propio discurso, acomodándolo a situaciones, personas y tiempos. Ignacio de Loyola había tenido una actitud muy rígida y había expulsado a muchos, se preciaba de ello incluso hablando con otros jesuitas al final de su vida: «vosotros a recibir y yo a echar» ${ }^{24}$. Esta actitud se reflejaba en las Constituciones que establecían en qué ocasiones un jesuita podía ser expulsado: si era incorregible en sus pasiones o vicios ofendiendo a Dios, y/o si su actitud y actuación eran contrarios al bien de la orden, al de sus hermanos de orden, o al de los de fuera de la Compañía. En la práctica cotidiana la distinción entre la primera causa de dimisión, la ofensa a Dios, y la segunda, la actuación contra la Compañía, tendía a difuminarse. Se estipulaba también que la dimisión de un miembro que había desarrollado un buen servicio o tenía habilidades debería ser más difícil que la dimisión de un jesuita poco útil. Asimismo, la Cartuja era el único destino plenamente aceptado por la orden para los dimitidos: una vida de trabajo, oración y silencio, sobre todo, silencio.

A medida que la Compañía creció el problema de los salidos se hizo más grave. En primer lugar por la sangría de efectivos. A. Lynn Martin ha llamado la atención, a partir de estudios para Francia e Italia centrados en las décadas finales del siglo XVI, sobre un hecho fundamental: la mayoría de los salidos eran jesuitas formados, coadjutores temporales y espirituales, con más de diez años en la Compañía. Era una pérdida que la Compañía no podía permitirse en un momento de crecimiento de los territorios de apostolado y de acrisolamiento de su imagen en Europa y el mundo. Las razones de ese desapego

22 ANDRADE, ACJB, Sección Diversa, signatura 113-01: 128.

23 RIBADENEIRA, ACJB, Sección Diversa, signatura ACDI 112-01: 133.

24 MHSI, Fontes Narrativi de S. Ignatio et de Societatis Iesu initiis, I, 739. 
hacia la Orden fueron múltiples. Los estudios mencionados inciden sobre todo en las crisis vocaciones de la mediana edad, momento en el que las expectativas de los jesuitas maduros no se verían cumplidas, bien por la dificultad de alcanzar el cuarto voto, la frustración de la ambición para algunos, bien por los desajustes de la estructura jesuita entre los diversos grados y la carga de trabajo en los ministerios activos de la Compañía... en última instancia, la exigencia absoluta de indiferencia al mundo y obediencia al superior, obediencia de acción, voluntad y pensamiento, convirtió a muchos disidentes en desobedientes ${ }^{25}$.

Ante este problema, la Compañía intentó aplicar diferentes estrategias en función de las problemáticas de cada individuo. Para los que apelaban a la necesidad de ayudar a sus padres, la Compañía buscó compensaciones que permitiesen a los jesuitas continuar en la orden. A los que mostraban un fervor tibio o poco acorde con los ministerios de la Compañía no se les permitía continuar su educación. En 1568 se exigió que se debía enseñar a otros lo que ya se sabía antes de continuar estudiando filosofía. La estrategia definitiva era, sin embargo, hacer difícil la partida especialmente para los miembros más valiosos: ralentización y dificultades para relevar de los votos, cárcel... y penas espirituales como la excomunión mientras no se obtuviese la dispensación de los votos... en algunos la huida pareció ser la única vía posible.

La primera medida, sin embargo, fue la centralización de la decisión de la expulsión. Sabina Pavone ha apuntado que el generalato de Francisco de Borja marcó un punto de inflexión respecto a la actitud de la Compañía en este aspecto. A su juicio Borja intentó evitar las dimisiones subrayando la importancia de cierta dulzura en el trato y reclamando la última decisión de estos casos para sí, en un intento por controlar la sangría de efectivos. Consiguió de Pío V en 1566 la reconfirmación de la prohibición de pasar a otra orden - con excepción de los cartujos- sin permiso del General y la excomunión para los salidos sin carta dimisoria. Aquellos que finalmente pasasen a otras órdenes, siempre con permiso del General, si finalmente no se acomodaban debían volver necesariamente a la Compañía ${ }^{26}$. El generalato de Claudio Aquaviva (1581-1615) profundizó en estas estrategias27. Por un lado, la normativización de la Compañía que caracterizó el generalato de Aquaviva trazó fronteras más claras en la identidad jesuita y en su acomodo al mundo, llevando a los márgenes de la Compañía a personalidades y sensibilidades singulares. Por otro lado, y al calor de la revuelta interna, la Compañía logró del Papado apoyos fundamentales para aplicar políticas internas estrictas respecto

25 LYNN MARTIN, 72/2 (Washington, 1986): 201-221.

26 PAVONE, 2011: 564-480.

27 MOSTACCIO, 2012. No he tenido ocasión de consultar la última aportación a este tema, MOSTACCIO: 2013. 
a esas «singularidades». Gregorio XIII por medio de la bula Ascendente Domino (25 de mayo de 1584) estableció que cualquiera que directa o indirectamente, bajo color de celo o de mayor bien o bajo cualquier otro pretexto, contradijese el Instituto de la Compañía o sus Constituciones o cualquier cosa concerniente a ellos, o procurara cambiarlos o alterarlos o ponerlos de otra forma o modo contrario a esas Constituciones o cualquier cosa sustancial al dicho Instituto, incurriría en excomunión e inhabilitación para cualquier oficio o beneficio secular o de cualquier orden secular o regular, reservada a la Santa Sede. En la misma bula se prohibía que ninguno dentro o fuera de la Compañía, sin licencia del General u otro superior, hiciese anotaciones, declaraciones, glosas o comentarios sobre el Instituto, Constituciones, Privilegios... se prohibía la interpretación de esos textos fundacionales y su enseñanza, y la circulación o posesión de manuscritos o impresos de este tenor. Se reiteraba que el abandono de la Compañía después de hechos los votos sin autorización del General significaba la excomunión completa y otras penas reservadas. Finalmente, aquellos que obtuviesen la licencia de la Compañía aportando causas no verdaderas o con engaños o cometiendo a propósito defectos graves serían censurados como apóstatas y su licencia quedaría sin efecto. Los que se aconsejasen de externos sin saberlo los provinciales para lograr ser licenciados de la Compañía serían excomulgados. Por su parte Gregorio XIV en la bula Ecclesiae Catholicae de junio de 1591 confirmó el modo de gobierno de la Compañía y el tratamiento que debían recibir los rebeldes. Lo sustantivo al Instituto y la Compañía fue definido en los decretos 44, 46 y 58 de la V Congregación. Y en el decreto 54 se ordenaba la delación, en virtud de santa obediencia, de todos los que se supiera que conspiraban o habían conspirado como participantes o como cómplices contra la Compañía. Y el decreto 2 de la VI Congregación (1608) obligaba también a la delación de los jesuitas que se sirviesen de la obra de otra persona, fuese de la Compañía o externa, para turbar la paz de la Compañía ${ }^{28}$.

El General Aquaviva intentó regular y moderar el inmenso crecimiento de la orden y al mismo tiempo consolidar lo logrado ${ }^{29}$. Promovió una renovación e intensificación de la vida espiritual de sus súbditos a través de la regulación de la oración, la meditación y los periodos de estudio, intentando al mismo tiempo eliminar todo fleco sospechoso de heterodoxia. Propuso una vuelta a las fuentes clásicas del monasticismo, sobre todo los textos de San Basilio y

28 ASV, Fondo Bolognetti, 322, ff. 226-227. Un dossier muy interesante en el que se asientan por la vía de la prohibición los límites que debían contemplar todos los jesuitas en relación a la salida, el voto de obediencia, castidad y pobreza, la enseñanza sobre el tiranicidio, la injerencia en las cosas de los libros y la impresión de libros, una recopilación del tiempo del General Oliva (1664-1681).

29 BROGGIO et al., 2007. 
San Bernardo sobre la vida sagrada... El enorme crecimiento de la Compañía, su trayectoria, sus ministerios en el mundo, generaron como contrapartida una multitud de frentes erosionadores: el debate sobre la gracia se desató en estos años, los problemas con la Ratio y la educación, la influencia creciente de los jesuitas en el confesionario de las elites, los conflictos con las otras órdenes en los territorios de misión... El General Aquaviva intentó gestionar el consenso y la disidencia siempre con un principio innegociable: era más importante salvar la reputación de la Orden que la de sus miembros particulares. Evitar el scandalum y guardar la pacem cum externis fue una preocupación constante de la Compañía, especialmente intensa en el siglo XVII, en relación directa a la escalada crítica de aquel siglo. La paz con los externos podía lograrse mediante el diálogo y la negociación pero evitar el escándalo era más difícilis.

La Compañía demostró una gran preocupación con el problema de los dimitidos precisamente porque era consciente del escándalo que proporcionaba, generalmente en relación con la imagen y la reputación de la Compañía. Este florecimiento de normativas y literatura disciplinante era la señal de una situación histórica muy lejos de ser disciplinada. ${ }^{31}$ Por ello debía medirse finamente la acción en función de si el escándalo resultante era peor que la conducta del dimitido; de si, a la postre, podían aplicarse las Constituciones negociando la obediencia o, incluso, silenciando discretamente la desobediencia.

\section{OBEDIENCIA NEGOCIADA, DESOBEDIENCIA SILENCIADA}

La negociación de la obediencia en España tuvo para la Compañía una zona de roce sensible: la Inquisición española. Para los que querían salir de la Compañía y no encontraban el camino una salida era la comisión de acciones que provocasen la expulsión por parte de los superiores. Los súbditos del rey Católico tenían otra opción de un peso indudable: apelar a la Inquisición.

La Compañía, desde sus mismos orígenes, intentó mantener una prudente distancia respecto al Santo Oficio, una distancia que se concretaba en la prohibición a los miembros jesuitas de aceptar oficios inquisitoriales y en el desarrollo de una estrategia de adaptación local en la aplicación de los privilegios de la Compañía que entraban en el campo de la Inquisición española (la autorización para leer libros prohibidos, para absolver del delito de herejía en el fuero de la conciencia). Se trataba de una acomodación política que tenía que ver con mantenerse a resguardo del tribunal, y sus mecanismos ex-

30 RURALE, 2005: 25-52.

31 FORESTA, 92 (Roma, 2012): 331. 
cepcionales para la persecución de la herejía, con complacer a los monarcas españoles que había hecho del Santo Oficio un signo de identidad en cuanto a símbolo de su lucha contra la herejía y en beneficio de la cristiandad. A pesar de estas disposiciones, los conflictos abundaron hasta poner a la Compañía contra las cuerdas en el dramático contexto de los años 90 del siglo XVI. La V Congregación General de 1593 ratificaría la voluntad de la Compañía de servir y no actuar contra los intereses políticos de Felipe II. Los jesuitas reconocían la jurisdicción de la Inquisición en materias antes privilegiadas para ellos, como la lectura de libros prohibidos y la absolución de herejes en el foro de la conciencia, y rompían la prohibición de que miembros de la Compañía aceptasen servir cargos en el Santo Oficio.

El General Aquaviva contentaba así a Felipe II. Pero los conflictos continuaron sucediéndose porque los jesuitas súbditos de la Monarquía española ya habían descubierto en el Santo Oficio una jurisdicción de enorme fuerza y presencia en las entretelas del poder de la Monarquía y un ariete en las relaciones Madrid-Roma. Por ello, para la Compañía solicitar el amparo del Santo Oficio era una desobediencia imperdonable, un acto de rebeldía de lesa majestad jesuita.

Son numerosos los ejemplos que podríamos traer aquí de jesuitas castigados por recurrir a la Inquisición y de obediencia negociada de jesuitas españoles levantada sobre la palanca del Santo Oficio. Traemos aquí sólo un ejemplo, el caso Abreo.

Francisco Abreo ${ }^{32}$ entró en la orden en Salamanca en 1569, con 31 años y una formación jurídica sólida, habiendo ocupado la cátedra de cánones y leyes de la universidad. Esta preparación fue determinante en la función que desempeñó dentro de la orden: se convirtió en asesor jurídico de las provincias de Castilla, Toledo y Aragón, además de actuar en pleitos en la corte en nombre de la Compañía. Este papel le proporcionó contactos, recursos económicos y una gran capacidad de influencia. Abreo intentó en varias ocasiones dejar estas ocupaciones, que le producían cierta «frialdad» espiritual, aunque sin éxito ${ }^{33}$.

En 1583 Abreo propuso realizar en beneficio de la Compañía, de sus privilegios e instituto, cinco tratados que abordasen el problema de la estructura interna de la orden. Según su experiencia, los jueces pretendían juzgar a los de la Compañía con el mismo derecho que al resto de las órdenes y ello era imposible por la diversidad de sus grados y estructura. Abreo pretendía asentar jurídicamente, «fijar en derecho» decía él, el Instituto y las Constituciones $^{34}$. Aquí empezaron los problemas para Abreo. Su propuesta encendió la

32 Francisco d'Abreu, contra Institutum, cc. 1588-1596, ARSI, Hist. Soc. 163, ff. 2-25.

33 ASTRAÍN, 1909, III: 354-357.

34 Francisco d'Abreu, contra Institutum, cc. 1588-1596, ARSI, Hist. Soc. 163, ff. 26-29. 
alarma. Su nombre, además, apareció vinculado a los memorialistas rebeldes, jesuitas de tanto crédito interno como Dionisio Vázquez, el que había sido secretario personal del General Francisco de Borja. La bula de Gregorio XIII de 1584 proporcionó a la Compañía un instrumento perfecto para controlar a un miembro que, con voluntad constructiva, pretendía interpretar la esencia de la orden, fijar con más claridad su estructura interna, sus procedimientos y tiempos, incluyendo algunas de las propuestas de los disidentes. Pero Abreo se negó a la expulsión sin más y a su inhabilitación. Tenía tras de sí numerosos contactos en la corte, en los consejos y en las audiencia, era conocedor profundo de las interioridades de la Compañía. ¿Le convenía a la Compañía ese escándalo?

Entre 1583 y 1587 el estatus de Abreo en la Compañía fue singular. Residió en el colegio de Bellimar, en Burgos, con su propia biblioteca, un hermano que le servía y otro escribiente y una renta en mano de 500 escudos de oro, «y en otro tiempo le concertaron pedir para sus alimentos y libros cantidad de ducados a personas seglares y prelados». La Compañía había optado por mantener a Abreo como un jesuita «dormido», pactando con él su silencio. Después de la congregación provincial de Castilla de 1587, en la que de forma unánime se pidió un comisario para España, la Compañía decidió controlar mucho mejor a Abreo, a quien consideraba líder del movimiento rebelde: se ordenó que sólo recibiese cien ducados por año y siempre a través del rector de la casa, reduciendo también su servicio a un único hermano ${ }^{35}$.

Abreo no aceptó las nuevas condiciones del pacto y presionó en un punto sensible para la Compañía: la Inquisición española. En 1588 dirigió un memorial al Santo Oficio donde plasmaba todas sus críticas y solicitaba el amparo del Tribunal ${ }^{36}$. Según Abreo las Constituciones eran papel mojado en manos de los superiores. Éstos alargaban las profesiones innecesariamente por dos razones principales. La primera, la económica, porque a los candidatos se les permitía mantener sus beneficios, préstamos y herencias otorgando el usufructo a la Compañía mientras no hiciesen votos. La segunda, por una ambición de poder inhumana, porque se hacía depender absolutamente del superior la vida del individuo:

este abuso se ha introduzido por tener oprimidos a los subjectos y para poderlos despedir y ocultar y trasponer quando y a donde les pareciere como lo han hecho y son ya tantos los despedidos como los que quedan ${ }^{37}$.

35 Carta del padre Villalba al General Aquaviva, 14/12/1587, ARSI, Ep. Hispaniae 143 (1587-1592), f. 103v.

36 Memorial del padre Abreo para el Licenciado Francisco Dávila, consejero de la Suprema, 1588, AA. EE., Santa Sede, Leg. 35. n. 5, ff. 170-177v.

37 AA. EE., Santa Sede, Leg. 35. n. 5, 175r. 
El despido no guardaba ninguna formalidad jurídica por lo que el despedido no podía defenderse de las acusaciones y el resultado eran manifiestas injusticias, con frecuencia producto de calumnias más que de faltas objetivas. Los salidos que ya habían hecho votos, al haber renunciado a las legítimas y sus propiedades, salían al mundo en la miseria más absoluta, para descrédito de la religión y el sacerdocio y escándalo de sus contemporáneos. Finalmente, la situación económica de la Compañía en España era terrible. El resultado es que se lanzaban a buscar dinero consiguiendo «la opinión y nota de cobdicia y los que buscan y allegan limosnas y dinero son los más aceptos y estimados de los superiores. Los proximos con esto son vexados y huyen...» ${ }^{38}$.

La reforma de la orden sólo podría venir de la propia Compañía, el Papa o el Rey. De la propia Compañía no se esperaba. El acceso al Papa era difícil y el General, tan cercano, lo cortocircuitaba. El Rey lo había intentado pero otras ocupaciones, como la guerra de Portugal, le habían distraído. Sólo quedaba un camino: la Inquisición,

Pues qué empresa se puede ofrecer más heroica ni más importante ni de más bien universal ni más digna deste Real Consejo y Santo Tribunal... y sería excusa el dezir que esto no toca ni pertenece a su jurisdicción porque muy propio y necesario officio suyo es y debe ser el proveer a los peligros que adelante pueden suceder en las cosas de la fe, y es evidente el que hay y puede haber en el gobierno que lleva la Compañía de una sola cabeza perpetua y de estrangero y de tanta dependencia como está probado ${ }^{39}$.

En paralelo al envío de este memorial a personas bien seleccionadas, Abreo solicitó dejar de ser de la Compañía de puertas para adentro o ser exento de la autoridad de los superiores aunque manteniendo los votos y la «devoción» ${ }^{40}$. Aún se puso otra carta en la mano: firmó una declaración bajo juramento en la que declaraba las malas acciones que había realizado contra el gobierno de la orden. El General Aquaviva no se avino al trato y en diciembre de 1588 firmó la carta dimisoria de Abreo sin ningún tipo de concesión. Abreo se negó a aceptarla y volvió a la carga. En marzo de 1589 solicitaba ser exento de la jurisdicción de todos los superiores y sólo estar sujeto al provincial de Castilla, Gil González, estar en el colegio de su elección y una renta fija de 150 ducados para su sustento y el de su compañero, y ser relevado de los votos.

$\mathrm{Al}$ parecer se llegó a un precario equilibrio que se rompió en 1591 con la bula de Gregorio XIV que autorizaba al General a actuar contra los rebeldes sin estrépito ni forma judicial. Aquaviva tenía las manos libres y lo único que

38 AA. EE., Santa Sede, Leg. 35. n. 5, 176r.

39 AA. EE., Santa Sede, Leg. 35. n. 5, 176v-177r.

40 ARSI, Hist. Soc. 163, f. 116. 
se las ataba era el miedo al escándalo y a la pérdida de reputación en un momento especialmente difícil para la Compañía. Felipe II había dado oídos a los memorialistas y había solicitado al General y al Papa la visita de la Compañía en España proponiendo sus propios visitadores, como el obispo de Cartagena Manrique de Lara, antiguo inquisidor. La Compañía se negó en redondo a la visita por un externo con esa trayectoria. Las tensiones diplomáticas fueron intensas en el eje Madrid-Papa-General.

En este contexto Abreo intentó salvarse del naufragio. En una carta al General desde Madrid afirmaba que él nunca había tenido intención de dejar la Compañía ni liderar ni sostener una revuelta («traer las cosas pasadas de nuevo al presente») sino sencillamente apartarse del conflicto. Había vuelto a ponerse el hábito de la Compañía pero ahora avergonzado porque había tantos jesuitas sin estudio y de baja condición que, si antes el hábito de la orden daba honra, ahora era él el que daba honra al hábito ${ }^{41}$. Se le había acusado de acudir a la Inquisición de España en el conflicto con la Compañía. No lo negaba, había buscado una plaza de consultor en la Suprema como mecanismo para protegerse de la orden, porque se sentía perseguido y sin apoyos; y la bula de Gregorio XIV, a su juicio subrepticia, que había dejado a los acusados de rebeldía absolutamente indefensos, le daba la razón. Insistía el jesuita en que sus quejas no estaban guiadas por el interés personal sino que eran el resultado de un análisis reposado del que había concluido un panorama desastroso para la Compañía en España, ya expuesto en el memorial de 1588, especialmente en los aspectos económicos. Había informado a varios superiores y la respuesta unánime es que no había remedio. La consecuencia de todo ello era que se buscaban más las bolsas que las almas y que las juntas y congregaciones sólo se ocupaban de estas cuestiones temporales (138). Así, «los que más dineros traen son los mas estimados y favorecidos y tenidos por mas útiles de los superiores y por dinero todo se disimula y se alcanza y así lo procuran» (138). De ahí el relieve de, por ejemplo, el padre Sicilia, una especie de conseguidor que se encargaba de buscar dinero para los colegios, incluso de formas poco ortodoxas, mientras todos miraban hacia otro lado sabiéndolo. El ejemplo máximo lo ofrecía el colegio de Madrid, una venta de negocios y negociantes en la que algunos jesuitas se pasaban semanas, meses y años cruzando calles y audiencias. El colegio era una plaza pública en la que se asentaban los pleiteantes a cuerpo de rey, se visitaban mujeres, se recibían visitas... La murmuración era continua porque todos querían controlar el poder de los demás para acrecentar el suyo. Y este cuadro era aplicable a muchos otros sitios. De religión sólo había el nombre y el hábito. Para Abreo la distancia entre el diseño original de la Compañía y su realidad cotidiana en el colegio de Madrid era tan abismal que resultaba increíble.

41 ARSI, Hist. Soc. 163, ff. 136-141. 
Para salvar ese abismo sólo veía Abreo dos opciones: o se cumplían las Constituciones a rajatabla o se actualizaban para adecuarlas a la realidad existente, por fea que esta fuese. Y esta última opción era la más factible. Los memoriales escritos por Abreo, que de los cinco previstos en 1583 fueron nueve, abarcaban todos los aspectos de la Compañía: los problemas temporales mencionados y también los espirituales, la fijación clara del tiempo de las profesiones, el tratamiento de la disidencia interna, las visitas de las provincias, la creación de comisarios para hacer más ágil la gestión... No olvidaba Abreo apostillar que Roma se movía por chismes y engaños, sin desentrañar la realidad de los problemas ni oír a las partes.

Porque defendía una solución real para esta situación crítica de la Compañía es por lo que querían silenciarlo mediante la expulsión. Para Abreo, como para muchos otros jesuitas, la expulsión era un problema vital, significaba encontrarse en el mundo tras más de quince años de servicios en la Compañía sin ningún tipo de cobertura económica, con frecuencia ni siquiera familiar y con las alas cortadas para desempeñar otras tareas. La expulsión sin carta dimisoria significaba estar excomulgado y por tanto no poder actuar como sacerdote ni optar a beneficios. Los salidos de las órdenes eran mal vistos por muchos obispos. Por ello, insistía Abreo al General, él nunca había querido dejar la orden sino que le despidiesen en secreto "para la seguridad de su conciencia», liberándolo de los votos pero «quedándome en lo demás», y esto para siempre, con el compromiso de que a pesar de tener más libertad, no le «era lícito mudanza por la honra del mundo». Parece que la razón para expulsarlo definitivamente que se le daba ahora es que ya había estado durante tres años como «huésped» y se había mostrado inútil para las cargas de la religión. Para Abreo este no era argumento: si había estado así por tres años podía seguir así perpetuamente ${ }^{42}$. La de Abreo no era una súplica humillada, al fin y al cabo tenía una baza en la mano, el precio del silencio de su pluma. No parece nada inocente que en carta a Aquaviva en enero de 1592 le informara que si dejaba la Compañía definitivamente, ésta debería pagar por los más de 300 pliegos que sobre todas las cuestiones relacionadas con la Compañía había escrito 43 .

En febrero de 1592 Abreo estaba en Madrid, donde se iban a celebrar Cortes, y había entregado al Rey sus nueve tratados, para temor de los propios jesuitas que avisaban que «ha de comenzar a aldear y tiene muchos amigos y favorecedores» ${ }^{44}$. Eran momentos muy difíciles para la Compañía en España. La visita estaba en curso. Se intentó sacar a Abreo de Madrid inútilmente. Se le vigilaba de cerca. El padre Gil González, visitador de las provincias de To-

42 ARSI, Hist. Soc. 163, ff. 145-147.

43 ARSI, Hist. Soc. 163, f. 143.

44 ARSI, Hist. Soc. 163, f. 149. 
ledo y Castilla, informaba sistemáticamente a Aquaviva de los movimientos del jesuita rebelde ${ }^{45}$. La situación era tan desesperada que algunos propusieron la fuga hacia delante: hacer profeso a Abreo «por sus méritos y para evitar inquietudes» ${ }^{46}$.

Sólo un mes más tarde, en marzo de 1592, el General Aquaviva daba unas instrucciones al provincial para cerrar el caso Abreo, instrucciones que definían incluso cómo debía planteársele la cuestión. En primer lugar se le había de informar de la concesión de un censo en el Colegio de Plasencia para cubrir sus gastos de por vida. Una vez aquietado con esta noticia se le debía pedir el juramento de guardar el secreto de todas las conversaciones que se mantuviesen en la negociación sobre su estatus futuro en la frontera de la Compañía. Una vez jurado el secreto, y sólo después de hacerlo, se le debía enseñar un billete de puño y letra de Aquaviva en el que se le daban cuatro días para dejar la orden y volverse a su casa. La negociación se daba por terminada. Se le negaba la vida en colegio ${ }^{47}$. Se le exigiría que todo se hiciese sin estrépito ni escándalo. Se le advertía que no se le ocurriese pleitear ni hablar del tema con nadie. Quizá nunca lleguemos a saber si la concesión del censo fue la contrapartida a las entregas de sus memoriales, la última de las cuales se produjo en abril de 1593. De la obediencia negociada de 1588 se pasó a la desobediencia silenciada ${ }^{48}$.

\section{¿EL TRIUNFO DE LA DESOBEDIENCIA?}

En relación con los salidos de la Compañía uno de los problemas últimamente mejor estudiados es el impacto que estos salidos tuvieron en la construcción de la imagen negativa de los jesuitas a través de una intensa guerra de papel que despegó con fuerza a principios del siglo XVII. Sin duda, uno de los textos más significativos de esa guerra fue el Monita privata, un panfleto escrito en 1614 por el jesuita polaco expulso Jerónimo Zahorowski, (a partir de la edición holandesa de 1654, Mónita secreta) ${ }^{49}$. Constaba de un prefacio corto y diecisiete capítulos, dieciséis originales más uno añadido en 1676. Un siglo después de la primera edición se habían realizado 40 ediciones más en diversas lenguas. Hasta el siglo XX se conocen más de 400 ediciones en Italia, Francia, Alemania, España y Suiza. La razón de su éxito estaba en que precisamente se presentaba como unas constituciones secretas de la Compa-

\footnotetext{
45 ARSI, Hist. Soc. 163, ff. 160-172.

46 ARSI, Hist. Soc. 163, ff. 152-153.

47 ARSI, Hist. Soc. 163, ff. 172-181.

48 ARSI, Hist. Soc. 163, ff. 182 y ss.

49 FRANCO y VOGEL, 2002. PAVONE, 2000.
} 
ñía de Jesús, conocidas sólo por unos cuantos padres por la naturaleza de su objetivo, la conquista del poder, y por el diseño de su estrategia: la persuasión y el dominio de las conciencias a través del jesuita confesor. Al final del texto se hacía hincapié en la necesidad de seguir manteniendo el secreto y por tanto, de responder de forma simulada y negativa a las posibles preguntas acerca de la existencia y contenido de estas constituciones secretas. Zahorowski había leído las auténticas constituciones y supo darle un perfil similar. En síntesis, el éxito del Mónita radicaba en la plausibilidad de su forma y contenido ${ }^{50}$.

En España fue Juan del Espino el responsable de la traducción y difusión del Mónita, junto a Juan de Roales. Según Astraín, Espino había sido jesuita en su juventud, expulsado de la orden había pasado al Carmelo de donde también había salido ${ }^{51}$. El Mónita, que había circulado manuscrito previamente, se imprimió en Madrid a finales de 1633 bajo el título Singulares y secretas admoniciones para particulares personas de nuestra Compañía, traducidas de latín en romance. A principios de 1634, había aparecido en Sevilla, anónimo y bajo el título Avisos secretos a los bien entendidos. La Compañía hizo correr la voz de que Espino era el autor del Mónita y fue preso en 1634. En su defensa Espino defendió, con análisis gramatical incluido, que el texto era obra del General Aquaviva 52 .

El reinado de Felipe IV fue especialmente favorable para la Compañía en España. Se abrió el Colegio Imperial de Madrid en 1629, los jesuitas ocuparon puestos claves en el confesionario del Conde-Duque, fueron considerados una autoridad intelectual a través de individuos como el padre Pineda, responsable del Índice de libros prohibidos de 1632, se ocuparon del púlpito de palacio con asiduidad (los padres Florencia, Albornoz, Pimentel)... No en vano se decía entonces que la mejor manera de medrar en la Corte era «oir siempre misa con la Compañía y dejarse ver con un rosario en las manos» ${ }^{53}$. Destacaron también los padres Poza y Salazar. El primero era considerado por algunos de sus enemigos como el "gran valido» del propio Olivares ${ }^{54}$. Hernando de Salazar, confesor del Conde-Duque, consiguió ser nombrado consejero de la Suprema en 1632.

Esta identificación con el proyecto olivarista de un sector importante de la Compañía en Madrid provocó un frente común entre antijesuitas y antiolivaristas y un plasma fluido a través del cual viajaron con rapidez panfletos y

50 PAVONE, 11/1 (Roma, 2003): 195-227.

51 ASTRAÍN, 1916, vol. V: 206. Hay que precisar, no obstante, que aunque Astraín suele estar muy bien informado, en los escritos de Espino nunca se reconoce esa pertenencia de juventud a la Compañía.

52 MORENO, 2010: 77-114.

53 LOZANO, 2005: 192.

54 MARAÑÓN, 1992: 237. 
libelos, como la Instrucción a los príncipes de cómo se gobiernan los padres jesuitas, un panfleto antijesuita atribuido a Fulgencio Micanzio, discípulo del veneciano Paolo Sarpi, publicado en Venecia en 1617 y prohibido por la Inquisición romana al año siguiente ${ }^{55}$.

La presencia de estos textos en la Corte y otras ciudades importantes como Salamanca ${ }^{56}$ llevaron a los jesuitas a presentarse ante el Rey y el Conde Duque en los primeros días de 1634 para pedir amparo ante lo que a su juicio era una auténtica conspiración ${ }^{57}$ La respuesta de Felipe IV fue inmediata a través del Santo Oficio. En marzo de 1634 la Inquisición prohibía el Monita bajo el título Admoniciones secretas. No dejaban de llover papeles contra la Compañía ${ }^{58}$. El 29 de junio de 1634 se organizaba un acto de quema de los libelos y panfletos. Pero la calma duró poco: en los primeros meses de 1635 aparecieron libelos en Madrid firmados por fray Tomás Gracián, expulso jesuita y ahora religioso de San Francisco. Las predicaciones y pasquines contra la Compañía inundaron Daimiel, Toledo y Madrid. En agosto de 1635 el Mónita se distribuía en Toledo. Aparecería después en Zaragoza y Granada.

La caída del Conde Duque a principios de 1643 obligó a un prudente realineamiento estratégico en busca de nuevas coberturas del poder. En noviembre y diciembre de 1643 el p. Gonzalo Peralta, de la casa profesa de Sevilla, denunciaba ante el Santo Oficio a varios padres carmelitas del convento de Jerez de la Frontera por difundir escritos de Espino como el titulado El Antichristo. En diciembre se publicaban edictos en Granada y Sevilla para recoger sus papeles. A principios de 1644 el padre Avilés, de la misma casa profesa, iniciaba una serie de respuestas a las críticas de Espino que, como era de esperar, tuvieron su consiguiente contra respuesta. En la Corte, los jesuitas celebraban varios encuentros con personajes de diversa entidad política en noviembre de 1643, individuos de tanto peso como el conde de Lemos, destacado antiolivarista. Todo parece indicar que los contactos dieron resultado y, aparentemente, la tensión se calmó.

Sin embargo, el Mónita dejó una huella profunda también en España. La credibilidad que ofrecía el documento dio a los detractores de la Compañía un marco lógico en el que las acciones jesuitas encontraban su sentido. Uno de los ejemplos más espectaculares de esta afirmación lo encontramos en un papel anónimo delatado al Santo Oficio en Madrid y Sevilla titulado Dudas pú-

55 AHN, Inquisición, leg. 4444, n. 58.

56 Carta del p. Andrés Mendo de Salamanca, al P. Rafael Pereira de Sevilla, 14 de enero de 1634. MHE, 1861, vol. XIII: 9.

57 Carta del P. Sebastián González de Madrid, al p. González de Mendoza, visitador de la provincia, 1 de febrero de 1634, MHE, 1861, vol. XIII: 11.

58 Carta del P. Andrés Mendo de Salamanca, al P. Rafael Pereyra de Sevilla, el 23 de febrero de 1634, MHE, 1861, vol. XIII: 24. 
blicas teológicas que consultan los señores de España a las universidades de Salamanca y Alcalá, de $1666^{59}$. Se trataba de treinta y siete preguntas que teóricamente se dirigían a las universidades mencionadas en el título buscando respuestas académicas, jurídicas y teológicas. En realidad, el tono era coloquial y buscaba conectar con un público mucho más amplio. Era un papel redactado inteligentemente, los interrogantes estimulaban la curiosidad de lectores y oyentes. El papel fue delatado porque atentaba contra el buen nombre de la Reina Mariana de Austria y sus actuaciones y, sobre todo, contra su confesor, valido y ahora Inquisidor General (1666), el padre Nithard. Probablemente ya se había distribuido en varias ciudades.

Sugerían las preguntas del texto que la Reina había traicionado la memoria de su marido al ordenar cosas que nunca se hubieran consentido, al favorecer al jesuita alemán hasta techos inimaginables y, sobre todo, se apuntaba que Nithard había llegado hasta donde había llegado poniendo en práctica las instrucciones secretas de los jesuitas. Se interrogaba el autor o autores sobre el futuro y el impacto que en los individuos, las instituciones, y en toda España podía tener la actuación de Nithard guiándose por el Mónita. Empezaba las preguntas subrayando los orígenes nacionales y familiares de Nithard, hijo de protestantes. ¿Era una persona fiable para ponerlo al frente del Santo Oficio? ¿Sería capaz de castigar a los herejes teniendo en cuenta que se había criado entre ellos? ¿O no? Desde luego, en este caso el Santo Oficio de España perdería su crédito y, quizá, entrarían las herejías que hasta ahora no habían conseguido vencer la resistencia de la Inquisición. Se podría pensar que un hombre solo no podría ser una amenaza tan enorme, pero si las plazas de las inquisiciones fuesen para padres de la Compañía o para sus adeptos en pocos años serían dueños de todas las Inquisiciones de España. Porque la experiencia dice «que esta familia favorece solamente a quien la sigue y persigue a quien no va con ellos». Y si toda la estructura de la Inquisición era hechura de la Compañía, ¿no se gobernaría el Santo Oficio a su medida, «castigando a quien ellos quisieren y a quien quisieren dejando sin castigos»? ¿Quién se atrevería entonces a delatar a sujetos sospechosos en doctrinas de la Compañía? ¿Y no se ensañarían con los frailes con los que tienen enemistad tradicional? ¿Qué pasaría con el secreto? Si el Inquisidor General comunicase cosas tocantes al oficio de la Inquisición con padres de la Compañía se pondría en riesgo el secreto, grave cosa para los acusados y el Tribunal. Y la posibilidad era bien real porque, como se ve en la advertencia trece «a los discretos en la Monita secreta de su orden», los jesuitas tenían mandato de comunicar a sus superiores toda la información. Y la falta de secreto ¿qué consecuencias podría tener para el gobierno de España? Si la Reina se confesaba con el Pa-

59 AHN, Inquisición, leg. 4432, exp. 20, s. f. Las citas que siguen se refieren todas a este expediente. 
dre Nithard y éste lo comunicaba a otras naciones enemigas el resultado podría ser muy dañoso para los intereses españoles. Esta duda se fundaba en el memorial contra la Compañía que el jesuita padre Hernando de Mendoza, había entregado a Clemente VIII, en el que se afirmaba «ningún secreto se guarda en la Compañía, aunque sea en confesión». La pregunta 21 iba con retranca:

Si en virtud de lo que manda el General de la Compañía en los avisos secretos... que dicen así: En todas las Provincias de Europa y fuera de ella ha de tener la Congregación una correspondencia fiel entre sí, avisándose unos a otros de lo que passa, así de las cosas propias como de las agenas, en todos los estados, modos y materias de gobierno, tratos de Reynos y Provincias. Dudase si será temeridad juzgar que el P. Confesor como tan observante en las cosas de su Religión cumpla con esta instrucción de su General en las cosas que se le comunicaren del gobierno de España y mayores interioridades de la Reyna.

Y la duda 23 no tenía desperdicio:

Si se puede creer que el P. Confesor aconseje a la Reyna las proposiciones más anchas y relaxadas con detrimento grave de su conciencia y de la justicia que según sus partes administra con sus vasallos? Estimase esta duda en lo que dice la Monita Secreta por la qual se gobiernan estos padres....: para gobernar las conciencias de los Principes y señores siganse las opiniones mas libres y no se sigan las de los frayles para que olvidados de sus doctrinas, sigan las nuestras».

Las dudas posteriores volvían a sugerir las consecuencias políticas que podrían surgir del nombramiento de un extranjero: ¿se podían repetir las Comunidades en Castilla? ¿Se revelarían los reinos de Aragón, Valencia y Cataluña? Incidían sobre la debilidad de la reina como mujer: ¿ ¿la tenía engañada el padre confesor? ¿No era él el responsable de que la leal nobleza ya no pudiese acercarse a la reina? No faltaban alusiones más personales, preguntas insidiosas sobre el familiar trato de la Reyna y el confesor. Finalizaba el documento con un par de preguntas que sugerían futuros alternativos: dada la situación descrita y los potenciales peligros, ¿podían los señores del gobierno asumir el control del reino, reinterpretar el testamento de Felipe IV y cambiar el modo de gobierno? Un cuestionario aparentemente inocente, un consulta teológica que no era tal, unos interrogantes que conducían de manera suave a interrogarse por una nueva desobediencia.

\section{CONCLUSIÓN}

Los jesuitas se han convertido en una clave de lectura de la modernidad como protagonistas de la Contrarreforma y de su presunta función moderni- 
zante. La Compañía, lejos de la imagen que quisieron proyectar, no fue una protagonista monolítica de la modernidad disciplinante, muy al contrario, fue un prisma de muchas caras, reflejo de la complejidad del paradigma tridentino. El éxito historiográfico de la Compañía en los últimos años se ha justificado por constituir un rico laboratorio en el que problemáticas políticas y culturales de alcance general para el mundo moderno podían ser estudiadas a escala y en geografías diversas. También la gestión de la disidencia debe ser incluida ahí. La modulación de la norma atendiendo a criterios de escándalo y reputación no fue privativa de la Compañía de Jesús sino la práctica cotidiana de un poder político y eclesiástico que, en proceso de afirmación y redefinición, debía medir finamente los límites de su actuación, buscando nuevos consensos internos y externos, y, finalmente, ajustando los mecanismos para reflejar diáfanamente la justicia distributiva del poder: el premio de la obediencia, el castigo de la desobediencia. El análisis de los textos de Bobadilla, Ribadeneira y Andrade a mi juicio sugieren una creciente rigidez crítica respecto a los salidos, desde mediados del siglo XVI a finales del siglo XVII, con narrativas de retribución cada vez más barrocas, llenas de apelación al miedo ${ }^{60}$. También una pérdida de capacidad autocrítica, ausente ya en Andrade. Sería el resultado de aplicar el principio ignaciano: importa más el bien de la Compañía que el de sus individuos en particular, a una trayectoria de la orden en la que corrían y se extendían en paralelo las luces y las sombras. Esa trayectoria ¿coincidiría con la pérdida de impulso de una Contrarreforma que se llenó de plasticidad barroca y se vació de sentido evangélico?

La Compañía negoció la obediencia y la desobediencia. Precisemos: lo hizo desde una posición de fuerza porque del superior dependía en sentido estricto la vida de los que pretendían salirse. Después de diez ó quince años en la Compañía, ¿qué opciones reales podía tener un jesuita disidente para sobrevivir fuera de ella? Por ejemplo, como pura hipótesis ¿hubiera podido el padre Mariana hacerse esa pregunta? El padre Ribadeneira, entrado tan niño en la Compañía, tan cercano a Ignacio, ¿cómo encajó, cómo lo hizo, la traición al espíritu del Loyola que supuso el decreto de la V Congregación de 1593 contra los conversos al establecer los estatutos de linaje de sangre?

Negociar la obediencia/desobediencia con el superior quizá era un mal menor, después de todo. Fuera de la Compañía, para hombres que habían sido formados en esa identidad y permanecido en ella por varios años, hacía mucho frío. La supervivencia dentro de la Compañía, para los críticos, era el precio de su silencio. Es sorprendente, desde este punto de vista el caso Abreo, la capacidad del individuo para utilizar sus escasos pero importantes recursos con una táctica efectiva, aunque a la postre no parece que le sirviera de mucho. El papel de la Inquisición española en todo este proceso no fue

60 SHORE, XV/2 (Budapest, 2010): 179-192. 
infrecuente en el marco de las relaciones de la Compañía con sus disidentes de la asistencia de España, ni, en un nivel político de mucho mayor calado, en las relaciones Madrid-Roma. Las vicisitudes de Abreo son también las de Enrique Enríquez, Hernando de Mendoza o, más avanzado el siglo XVII, las del padre Juan Bautista Poza, y las de tantos otros que aquí no hemos podido ver. Un repaso a la Historia de la Compañía de Antonio Astraín nos permitiría hacer un catálogo muy interesante. En el otro lado del caso Abreo está el General Aquaviva: el periodo de su largo generalato, entre 1581 y 1615, marca el final y el principio de una nueva etapa. Se dejaron atrás los lastres de una Compañía carismática en la que el espíritu todavía tenía un papel central para, en nombre de la eficacia y la reputación del poder, consolidar y redefinir estructura y, en definitiva, identidad. La escalada política de la Compañía tuvo mucho que ver en ello.

Esa escalada fue también su tumba. Subió muy alto. La caída fue estrepitosa. Críticos jesuitas y exjesuitas jugaron un papel crucial. Algunos de ellos, incluso los que tenían un espíritu constructivo, proporcionaron argumentos acreditados contra la Compañía. La difusión en España del Mónita y otros textos, críticos respecto a hechos objetivos o inventados, encontraron un caldo de cultivo que alimentó las teorías conspiracionistas. A pesar de la apelación al Santo Oficio, esta vez por parte de la Compañía, los textos corrieron como la pólvora. La numerosa presencia de copias impresas y manuscritas en los archivos y bibliotecas españolas lo atestigua. A finales del siglo XVII, como hemos visto, ya era posible interpretar la política del padre Nithard, valido, confesor e Inquisidor General en el marco interpretativo del Mónita. Ya no era un supuesto texto oculto que guiaba a los jesuitas en la intimidad del confesionario de príncipes y viudas. Ahora, el Mónita era la secreta hoja de ruta de Nithard. Por ello era posible sugerir suavemente, a través de un interrogante, un golpe de estado que derrocando al conspirador jesuita cambiase la forma de gobierno de la Monarquía española.

\section{BiBLIOGRAFIA}

Alfieri, Fernanda y Ferlan, Claudio, «Storie di oobedienza negoziata», en Fernanda Alfieri y Claudio Ferlan (eds.), Avveture dell'obbedienza nella Compagnia di Gesú. Teoria e prassi fra XVI e XIX secolo, Bologna, Il Mulino, 2012.

Astraín, Antonio, Historia de la Compañía de Jesús en la asistencia de España, vols. I-VII, Madrid, Razón y Fe, 1902-1925.

Broggio, Paolo, et al., I gesuiti ai tempi di Claudio Acquaviva. Strategie politiche, religiose e culturali tra Cinque e Seicento, Brescia, Morcelliana, 2007.

Catto, Michela, La Compagnia divisa. Il dissenso nell'ordine gesuitico tra '500 e ‘600, Brescia, Mocelliana, 2009. 
Foresta, Patrizio, «De su Alteza es mandar y de nosotros obedecer. Riflessioni sub obedienza e disobbedienza nei primi gesuiti», Quellen und Forschungen aus Italienischen Archiven und Bibliotheken 92 (Roma, 2012), 328-358.

Franco, José Eduardo y Vogel, Christine (ed.), Monita secreta. Instruçôes Secretas dos Jesuítas. Historia de un Manual Conspiracionista, Lisboa, Roma Editora, 2002.

Fumaroli, Marc L'École du silence. Le sentiment des images au XVIIe siècle, Paris, Flammarion, 1998.

García Cárcel, Ricardo, «La crisis de la Compañía de Jesús en los últimos años del reinado de Felipe II (1585-1598)», en Luis Antonio Ribot (coord.), La monarquía de Felipe II a debate, Madrid, Sociedad Estatal para la Conmemoración de los Centenarios de Felipe II y Carlos V, 2000: 383-404.

Gay, Jean-Pascal, Jesuit Civil Wars. Theology, Politics and Government under Tirso González (1687-1705), Farnham, Ashgate, 2012.

Lozano, Julián J., La Compañía de Jesús y el poder en la España de los Austrias, Madrid, Editorial Cátedra, 2005.

Lynn Martin, A., «Vocational Crises and the Crisis in Vocations among Jesuits in France during the Sixteenth Century», en The Catholic Historical Review 72/2 (Washington, 1986), 201-221.

Marañón, Gregorio, El Conde-duque de Olivares: la pasión de mandar, Madrid, Espasa Calpe, 1992.

Memorial Histórico Español. Cartas de algunos padres de la Compañía de Jesús. Tomos XIII y XVI, Madrid, Imprenta Nacional, 1861-1862.

Mir, Miguel, Historia interna documentada de la Compañía de Jesús, Madrid, 1913.

Moreno Martínez, Doris, «La aportación española al debate sobre la obediencia ciega en la Compañía de Jesús durante el Papado de Sixto V (1585-1590)», Investigaciones históricas: época moderna y contemporánea 33 (Valladolid, 2013): 63-88.

Moreno Martínez, Doris, «Las sombras de la Compañía de Jesús en la España Moderna, siglos XVI-XVII», en José Luis Betrán (coord.), La Compañía de Jesús y su proyección mediática en el mundo hispánico durante la Edad Moderna, Madrid, Sílex, 2010: 77-114.

Mostaccio, Silvia, «Declinare l’obbedienza fuori e dentro la Compagnia. L'approccio gesuitico sotto il generalato di Claudio Acquaviva», en José Martínez Millán, Henar Pizarro Llorente y Esther Jiménez Pablo (coords.), Los jesuitas: religión, política y educación (siglos XVI-XVIII), vol. II, 2012: 995-1006.

Mostaccio, Silvia, Early Modern Jesuits Between Obedience and Conscience, Ashgate Publishing, 2013.

O’Neill, Charles E. y Domínguez, Joaquín María (dirs.), Diccionario histórico de la Compañía de Jesús (DHCJ), Roma-Madrid, Universidad Pontificia de Comillas, 2001.

Pavone, Sabina, «Giano Bifronte: La Compagnia di Gesù tra Imago primi saeculi (1640) e antijesuitismo secentesco», en Thomas M. McCoog, SJ (ed.), Ite in- 
flammate omnia, Bibliotheca Instituti Historici Societatis Iesu, vol. 72, Roma, Institutum Historicum Societatis Iesu, 2010: 229-254.

Pavone, Sabina, «I dimissi dalla Compagnia negli anni del generalato di Francesco Borgia: Una nuova questione storiografica», en E. García Hernán, $\mathrm{M}^{\mathrm{a}}$ del Pilar Ryan, editores, Francisco de Borja y su tiempo. Política, religión y cultura en la Edad Moderna, Valencia-Roma, 2011: 465-480.

Pavone, Sabina, «Ribelli, seduttori, machinatori, impostori»: il complotto gesuita e la sua origine secentesca», en Roma Moderna e Contemporánea 11/1 (Roma, 2003): 195-227.

Pavone, Sabina, Le astuzie dei gesuiti, Roma, Salerno Editrice, 2000.

Rurale, Flavio, «La Compagnia di Gesù tra riforme, controriforme e riconferma dell?istituto (1540-inizio XVII secolo)», en Cheiron: materiali e strumenti di aggiornamento storiografico 43/44, 1/2 (Roma, 2005): 25-52.

Salviucci Insolera, Lydia, L'Imago Primi Saecoli (1640) e il significato deIl'immagine allegorica nella Compagnia di Gesù. Genesi e fortuna del libro, Roma, Editrice Pontificia Università Gregoriana, 2004.

Scaduto, Mario, SI, «Il Libretto consolatorio di Bobadilla a Domènech sulle vocazioni mancate (1570)», en AHSI, 43/85 (Roma, 1974), 85-101.

Shore, Paul, «Mission mostly accomplished: narratives of jesuit successes and failures in Hungary and Transylvania, 1640-1771», Universitatis Miskolcinensis. Sectio Philosophica, Tomus XV, Fasciculus 2 (Budapest, 2010): 179-192.

Recibido: 31/12/2013

Aceptado: 17/06/2014 